\title{
Nanoporous Copper-Nickel - Macroscopic bodies of a strong and deformable nanoporous base metal by dealloying
}

\author{
Lukas Lührs ${ }^{\mathrm{a}, *}$, Jörg Weissmüller ${ }^{\mathrm{a}, \mathrm{b}}$ \\ a Institute of Materials Physics and Technology, Hamburg University of Technology, Hamburg, Germany \\ ${ }^{b}$ Institute of Materials Research, Materials Mechanics, Helmholtz-Zentrum Geesthacht, Geesthacht, Germany
}

Abstract

Uniform macroscopic samples of nanoporous metal with high deformability have so far been limited to precious metals such as $\mathrm{Au}, \mathrm{Pd}$ and Pt. Here we propose nanoporous Copper-Nickel (npCN) as a nanoporous base metal that can be made with mm dimensions and exhibits significant deformability. NpCN forms a uniform bicontinous network structure with feature sizes that can be controlled from 13 to $40 \mathrm{~nm}$ by thermal annealing. Continuous compression tests confirm ductile deformation behavior accompanied with a high strength compared to macroporous $\mathrm{Cu}$ - and Ni-foams with similar solid fraction.

Keywords: Nanoporous base metal, Mechanical properties, Nanostructure, Porous material, Mesoporous metal

\section{Introduction}

In the field of tailor-made nanomaterials, nanoporous metals made by dealloying promise significant functionalization due to their very large surface area and high structural integrity. Potential applications arise as actuators [1] , sensors [2, 4], catalysts [5, 6], microfluidic pumps 7], bioanalytical systems 8 and structural materials with tunable mechanical properties [9-13]. Three properties are generically important for the materials performance in these fields: Affordability is an obvious requirement. Furthermore, deformability is required for avoiding premature failure upon exposure to stress concentrations or to designed mechanical load. Lastly, resistance against oxidation and corrosion are relevant, most importantly when potential cycles in electrolyte are to provide the functionalization.

So far, good mechanical behavior of nanoporous materials with macroscopic dimensions - several mm or more appears to be limited to precious nanoporous metals. Deformability in nanoporous $\mathrm{Au}$ has been observed in smallscale [14 18] and macro-scale testing [19 22]. Also studies on nanoporous Pt 23 or Pd 24 have demonstrated plastic deformation behavior during macroscopic mechanical testing. While these materials have a good stability against the environment, they are costly.

Since the above precious metals are electropositive, they can be conveniently dealloyed in aqueous solution. Macroporous bodies of more abundant and affordable metals are obtained by liquid metal dealloying. Macroporous titanium, niobium, or stainless steel have been demonstrated in this way 25 28]. Yet, dealloying in liquid metal

*Corresponding author. E-mail: lukas.luehrs@tuhh.de is experimentally more onerous than aqueous dealloying. Furthermore, liquid metal dealloying typically yields ligament sizes well above hundred nanometers, preventing the study of many of the size effects that are required for functionalization or for studies of small-scale plasticity. Here, we demonstrate a convenient process, based on aqueous dealloying, towards nanoporous base metals which provide a low-cost alternative.

$\mathrm{As} \mathrm{Cu}$ is rather electropositive, it is a natural candidate as an affordable material for dealloying processes based on corrosion in aqueous media. Nanoporous $\mathrm{Cu}$ has been prepared by dealloying from various alloys compositions that include - next to $\mathrm{Cu}$ - Mn 6, 29, 30, Al [31, 32, and $\mathrm{Zn}$ 32, 33, respectively. However, while $\mathrm{Cu}$ in clean air forms a thick oxide layer that passivates the surface [34, $\mathrm{Cu}$ and its oxides are readily dissolved in numerous electrolytes when oxygen is present 35. $\mathrm{Ni}$, on the other hand, forms a stable passive layer in air and in many acidic and alkaline corrosive environments 36 38. Several studies report the fabrication of nanoporous Ni using Mn-Ni precursor alloys 3944 . Yet, the preparation of mechanically resilient nanoporous Ni remains a challenge, as is demonstrated by the brittle behavior observed in several studies [43 45].

Our preparation strategy explores alloys of $\mathrm{Cu}$ and $\mathrm{Ni}$ as promising candidates for combining the comparative ease of dealloying and the malleability of $\mathrm{Cu}$ with Ni's potential for passivation. We present nanoporous Copper-Nickel ("npCN") as low cost, deformable and inert nanoporous metal. Copper-Nickel, also known as Chineseor German Silver, has been used in coin production for almost two millennia 38, 46. Its field of application has been extended to modern marine applications due to its excellent corrosion resistance [47, 48.

Alloys of $\mathrm{Cu}, \mathrm{Ni}$ and $\mathrm{Mn}$ are miscible at elevated tem- 
perature and so can be homogenized as solid solutions 49 51, a prerequisite for making uniform nanoporous structures by dealloying [52. We prepare npCN by electrochemically dealloying $\mathrm{Mn}-\mathrm{Cu}-\mathrm{Ni}$, so that the preparation relies on base metals only. $\mathrm{NpCN}$ takes the form of macroscopic monolithic bodies, free of dealloying-induced cracks. There microstructure exhibits a network of ligaments with diameters of $13 \mathrm{~nm}$. Thermal annealing allows for controlled coarsening of the ligament size up to $40 \mathrm{~nm}$. We show that npCN is strong and deformable in compression.

\section{Preparing nanoporous Copper-Nickel}

The precursor alloy $\mathrm{Cu}_{20} \mathrm{Ni}_{10} \mathrm{Mn}_{70}$ was based on $\mathrm{Cu}$ and Ni metal wires (99.98+\% metal-base purity) and electrolytic Mn granulate $(99.99 \%)$. Prior to alloying, superficial oxides of the $\mathrm{Mn}$ were removed using $1 \mathrm{M}$ oxalic acid. Ingots of the precursor alloy were obtained by melting in a cold-crucible induction furnace. Afterwards, the precursor alloy was annealed at $850^{\circ} \mathrm{C}$ for $\sim 12 \mathrm{~h}$ and quenched in water. From this master alloy cylindrical samples were turned to a diameter of around $1.1 \pm 0.05 \mathrm{~mm}$ using a lathe and cut into cylinders with a length of $1.8 \pm 0.1 \mathrm{~mm}$.

Electrochemical dealloying used a three electrode setup, with the precursor alloy clamped and electrically connected with gold wire, a graphite rod as counter electrode and $\mathrm{Ag} / \mathrm{AgCl}(3 \mathrm{M} \mathrm{KCl},+210 \mathrm{mV}$ vs. standard hydrogen) as reference electrode. An aqueous solution prepared with high purity water $(18.0 \mathrm{M} \Omega \mathrm{cm}), 1 \mathrm{M} \mathrm{KCl}$ $(\geq 99.5 \%$ purity) and $10 \mathrm{mM} \mathrm{HCl}(\geq 99 \%)$ served as the electrolyte; its $\mathrm{pH}$ value was measured as 1.8. Potentiostatic dealloying at $-620 \mathrm{mV}$ vs. $\mathrm{Ag} / \mathrm{AgCl}$ was stopped when the current dropped to $<10 \mu \mathrm{A}$. The material was then polarized at $-520 \mathrm{mV}$ until the current diminished to zero, which removed further $\mathrm{Mn}$. In order to avoid cracks induced by capillary forces during drying, the wet nanoporous samples were then immersed in Ethanol for around $2 \mathrm{~h}$ followed by $\mathrm{n}$-Pentane for $\geq 12 \mathrm{~h}$ and finally dried in air. This adopts a protocol from Ref [53]. A fraction of the samples were annealed in purified Argon gas (Oxygen and $\mathrm{H}_{2} \mathrm{O}$ content $<1 \mathrm{ppm}$ ) at $400^{\circ} \mathrm{C}$ for 20 , 30 and $45 \mathrm{~min}$. Scanning electron microscopy was used to determine the mean ligament size, i.e. the diameter of connecting elements between nodes.

Compression tests with a constant engineering strain rate of $10^{-4} \mathrm{~s}^{-1}$ were performed using an universal testing machine equipped with a $2 \mathrm{D}$ digital image correlation (DIC) system (DaVis 8.3.1, LaVision). A pre-load of $1 \mathrm{~N}$ was applied at the beginning of each measurement. The DIC setup enables in situ full field mapping of the sample's surface deformation in the camera's field of view. Images of the test setup and camera details are shown in Ref [54] and in the supporting online material of Ref [13, respectively. Image correlation used a pixel size of $6-7 \mu \mathrm{m}$, a step size of 8 pixels and a subset size of 25 pixels. Prior to testing, an airbrush system was used for applying a speckle pattern on the sample's lateral surface. This we found to greatly increase contrast and accuracy of the DIC measurement. The paint creates speckles with sizes from approximately 18 to $56 \mu \mathrm{m}$. Electron microscopy confirmed that paint did not enter the sample interior.

\section{Structural characterization}

The photographs of Fig 1 (a) illustrate geometry and optical appearance of samples in various stages of preparation: From left to right, a machined master alloy sample, an as-dealloyed npCN sample and an annealed npCN sample prepared for mechanical testing by spray-painting. As-dealloyed npCN takes on a matt dark brown color. Annealing brings the color closer to metallic copper, as can be seen on the paint-free end of the sample. The optical macrographs show monolithic bodies with no apparent macroscopic cracks. The annealed sample in Fig 1 (a) has an airbrush paint pattern for DIC applied to its side surfaces, as explained above.

Figure 1 (b) illustrates the grain structure of the master alloy by means of an electron backscatter diffraction (EBSD) image. Grain boundaries are highlighted. The analysis finds a single-phase face-centered cubic crystal structure, confirming successful homogenization and quenching. At an average size of roughly $500 \mu \mathrm{m}$, the grains are quite large. The figure indicates texture in the grain shape which - in view of the sample orientation in the ingot - is consistent with the direction of solidification, from the walls of the cold crucible into the melt.

Figure 11 shows scanning electron micrographs of asdealloyed npCN (subfigures (c, e)) and npCN annealed for $45 \mathrm{~min}(\mathrm{~d}, \mathrm{f})$ at different magnifications. The images were obtained on cross-sections of samples that were intentionally cleaved using a scalpel. It can be seen that the material exhibits a homogeneous bicontinuous structure, quite similar to that of macroscopic nanoporous gold [4, 9, 20. Except for elongated pores, a few tens of nm in size, and in contrast to other studies on macroscopic nanoporous base metals 29, 43, no dealloying-induced cracking is observed in $\mathrm{npCN}$. In the as-dealloyed state the ligament size was identified as $13 \pm 4 \mathrm{~nm}$; measurement uncertainties represent the standard deviation. In analogy to nanoporous gold [55, the ligament size of $\mathrm{npCN}$ can be easily controlled by thermal coarsening. After annealing at $400^{\circ} \mathrm{C}$ for 20, 30 and $45 \mathrm{~min}$, corresponding ligament sizes ensued to $22 \pm 6,32 \pm 8$ and $40 \pm 14 \mathrm{~nm}$, respectively.

Figures 1 (e) and (f) reveal that the ligaments of npCN are built of polyhedral elements; an indication of grooves can be seen where these elements are joined. The observation suggests that the ligament network is made of nanocrystallytes with a grain size that agrees with the ligament size. In this respect, $\mathrm{npCN}$ is distinguished from nanoporous gold, where the grain size is orders of magnitude larger than the ligament size [20]. Grain boundary grooves might be seen as sites promoting pinch-off and loss of connectivity during coarsening. Yet, the ligament network of npCN appears to retain its connectivity and to 

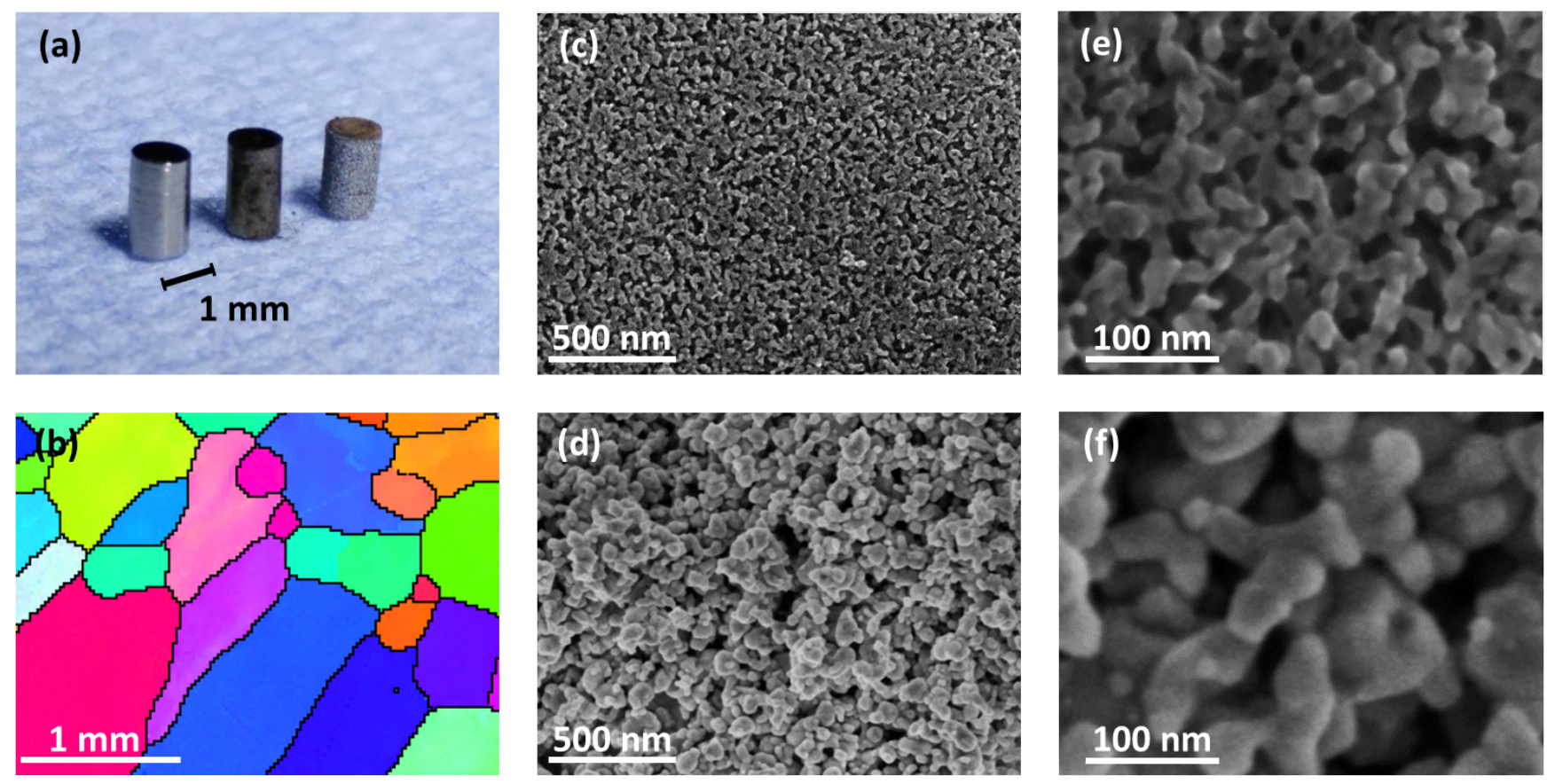

Figure 1: Structural characterization of nanoporous Copper-Nickel (npCN). (a) Photographs of (left to right) $\mathrm{Cu}_{20} \mathrm{Ni}_{10} \mathrm{Mn}_{70}$ precursor, as-dealloyed npCN and annealed npCN prepared for mechanical testing. Annealed sample has a speckled pattern applied; the sample was made from a slightly smaller master alloy than the remaining two. (b) Electron backscatter diffraction image (inverse pole figure coloring) Showing the microstructure of the master alloy. Grain boundaries are highlighted as black lines. (c-f) Scanning electron micrographs of cross-sectional areas in as-dealloyed npCN (c,e) and npCN annealed for $45 \mathrm{~min}$ in Ar gas at $400^{\circ} \mathrm{C}(L \approx 40 \mathrm{~nm})(\mathrm{d}, \mathrm{f})$ at different magnifications. Ligament sizes are 13 and $40 \mathrm{~nm}$ for as-dealloyed and annealed states, respectively.

coarsen in an essentially self-similar fashion. This is significant in the interest of mechanical performance of annealed samples with larger ligament size.

Density and solid volume fraction were determined through the assessment of the apparent sample volume by means of a measurement microscope and mass. Irrespective of the thermal treatment, density and solid volume fraction were measured to $2.75 \pm 0.11 \mathrm{~g} / \mathrm{cm}^{3}$ and $0.31 \pm 0.01$, respectively. In opposition to nanoporous gold [13, 54, 56 and macroscopic nanoporous nickel 43 npCN exhibits little shrinkage during dealloying and - even more significantly - during annealing.

Using energy dispersive X-ray analysis we find the $\mathrm{Cu}$, $\mathrm{Ni}$ and Mn composition of dealloyed npCN to be $60 \pm$ 6 at. $\%, 32 \pm 4$ at.\% and $8 \pm 2$ at.\%, respectively.

\section{Mechanical properties}

Figure 2 shows the results of continuous compression tests of npCN. The graph shows engineering stress versus engineering strain plots of as-dealloyed npCN (black line) as well as samples annealed for 20,30 and $45 \mathrm{~min}$ at $400^{\circ} \mathrm{C}$ with corresponding ligament sizes. Analog to previous studies on nanoporous base metals [29, 31, 43, 45, 57, asdealloyed npCN shows brittle deformation behavior upon compression. Still, with a compressive and fracture stress of more than $50 \mathrm{MPa}$, respectively, as-dealloyed npCN is strong compared to other nanoporous metals, such as those of Refs [19, 20, 32, 57, 58.

$\mathrm{NpCN}$ is also stronger than macroporous copper and nickel foams with a similar solid fraction, which exhibit yield stress values of around $5 \mathrm{MPa}$ for Ni- [59, 60] and up to $7 \mathrm{MPa}$ for $\mathrm{Cu}$ foams 61, 62.

At the origin of the exceptional mechanical performance of our nanoporous base metal is on the one hand the absence of the dealloying-induced cracks that are observed in other studies [29, 43. On the other hand, the high strength may also be a result of the small ligament size. Studies on nanoporous gold [15, 16, 19, 20, have confirmed the trend of "smaller is stronger" that originally emerged from microcolumn compression experiments on bulk gold [63, 64].

In addition, due to the high surface area to volume ratio of $\mathrm{npCN}$ the nature of the surface may influence its mechanical performance. As described earlier, $\mathrm{Cu}$ and $\mathrm{Ni}$ readily form an oxide layer on the materials surface. During deformation, the dislocation motion can be impeded through pinning of dislocation endpoints at the adsorbed surface layer, a mechanism known as "adsorption locking" 65. This effect has been exploited for tuning the flow 


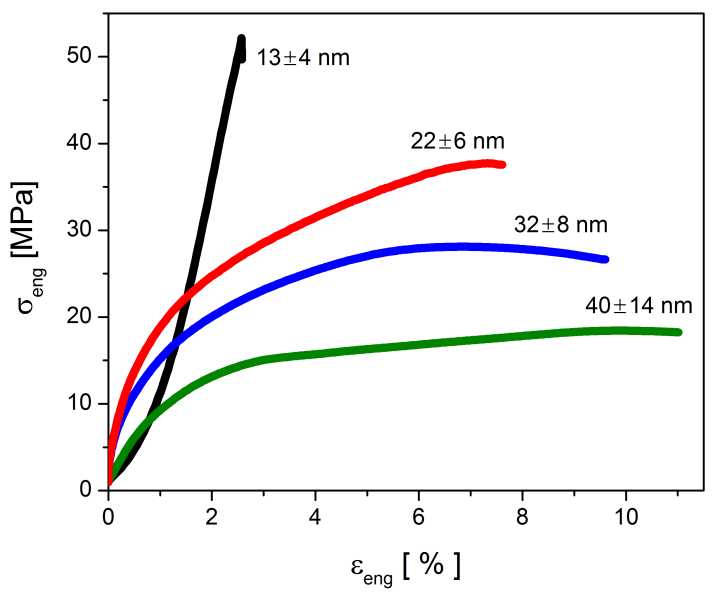

Figure 2: Compression tests on nanoporous Copper-Nickel $(\mathrm{npCN})$. Engineering stress plotted vs. engineering strain for npCN with varying ligament sizes, $L$. While the as-dealloyed material (black line) exhibits brittle deformation behavior, annealed npCN reveals significant ductility that increases with further coarsening of the ligament structure.

stress of nanoporous gold. In such experiments, electrochemically controlled oxidation affords high strengthening through the reversible formation of an adsorbed oxide layer [9].

Another conceivable origin of the high strength of npCN might be solid solution strengthening. Indeed, macroscale compression tests on elemental nanoporous $\mathrm{Cu}$ (no solid solution hardening) report fracture- and yield strength not exceeding $6 \mathrm{MPa}$ [31, [57], substantially less than what is achieved here with npCN. Microscale tests in Ref 32 find hardness values of around $20 \mathrm{MPa}$ for nanoporous $\mathrm{Cu}$ with a similar volume fraction. Hardness values of nanoporous metals have been identified with the yield strength [16, yet there are also arguments towards a more classic picture where the yield strength corresponds to $1 / 3$ of the hardness [20]. Furthermore, yield strengths obtained from microscale testing in nanoporous metals systematically exceed values found by macroscopic testing schemes 22]. This complicates comparisons between both testing methods. In any case, our macroscopic tests find the strength of npCN significantly higher than that of pure nanoporous $\mathrm{Cu}$.

Compression tests of annealed npCN show considerable ductility that becomes more pronounced with increasing ligament size, $L$. With the notion of a "smaller is stronger" relation in mind the origin of the decrease in strength becomes obvious as the strengthening size effect diminishes with increasing $L$. Yet, even at $L \approx 40 \mathrm{~nm}$ and with a yield strength of $\geq 10 \mathrm{MPa} n p C N$ exhibits a higher strength than macroporous $\mathrm{Cu}$ - and $\mathrm{Ni}$-foams with a similar solid fraction [59 62]. While high deformability in compression has been reported for some noble nanoporous metals [20, 23, 24, we here provide the first report of a deformable nanoporous base metal. This is of importance since deformability - and, with it, damage tolerance - is a prerequisite for application.

Strain maps calculated with digital image correlation of annealed npCN during plastic deformation are shown in Figure 3. Colors indicate the axial strain (top row of the figure) or the maximum two-dimensional shear strain on the sample surface. The images show npCN with $L \approx 22 \mathrm{~nm}, 32 \mathrm{~nm}$ and $40 \mathrm{~nm}$, respectively, at an average compressive engineering strain of $4.4 \%$ in loading direction. Axial strain maps (a-c), i.e. deformation in loading direction, find patches or bands of localized deformation with significantly higher straining compared to the surrounding material. An apparently similar deformation behavior is common in macroporous metallic foams in the form of "crush bands" 66, 67]. However, the formation of crush bands in foams is carried by a collective collapse of adjacent cells, and it results in a stress drop. Compression tests of npCN (Fig.2) reveal no stress maximum at early loading stages but on the contrary show distinct hardening during plastic deformation analog to macroscopic nanoporous gold [9, 11, 13, 20, 22, 54. Also EBSD analysis of nanoporous $\mathrm{Au}$ at different loading stages shows no formation of localized crush bands [20. Instead inhomogeneous maximum shear strain distributions (d-f) suggest that the strain concentration during plastic deformation of annealed npCN can be attributed to shear deformation. This deformation ultimately leads to failure.

\section{Conclusion}

We have developed nanoporous Copper-Nickel (npCN), a new macroscopic nanoporous metal solely created from base metals. Single-phase $\mathrm{Cu}_{20} \mathrm{Ni}_{10} \mathrm{Mn}_{70}$ precursors were electrochemically dealloyed in $1 \mathrm{M} \mathrm{KCl}$ and $10 \mathrm{mM} \mathrm{HCl}$ electrolyte and carefully dried. Annealing the samples allowed for a controlled coarsening of the porous structures. Using electron microscopy we find homogeneous bicontinous network structures free of dealloying induced cracks with ligament sizes in the range of $13-40 \mathrm{~nm}$, depending on the annealing conditions.

The mechanical performance of $\mathrm{npCN}$ was characterized via continuous compression testing. We find a high strength that exceeds values reported for macroporous metallic $\mathrm{Cu}$ - and $\mathrm{Ni}$-foams, as well as pure nanoporous $\mathrm{Cu}$ with a similar volume fraction. We discussed the underlying strengthening mechanisms.

Most importantly we observe significant plastic deformation during mechanical testing, an essential advance for a nanoporous base metal produced by electrochemical dealloying. The deformability becomes more pronounced with increasing ligament size. We argue that both, the deformability as well as the low priced raw materials of nanoporous Copper-Nickel represent a important step for future industrial usage of tailor-made nanoporous metals. 

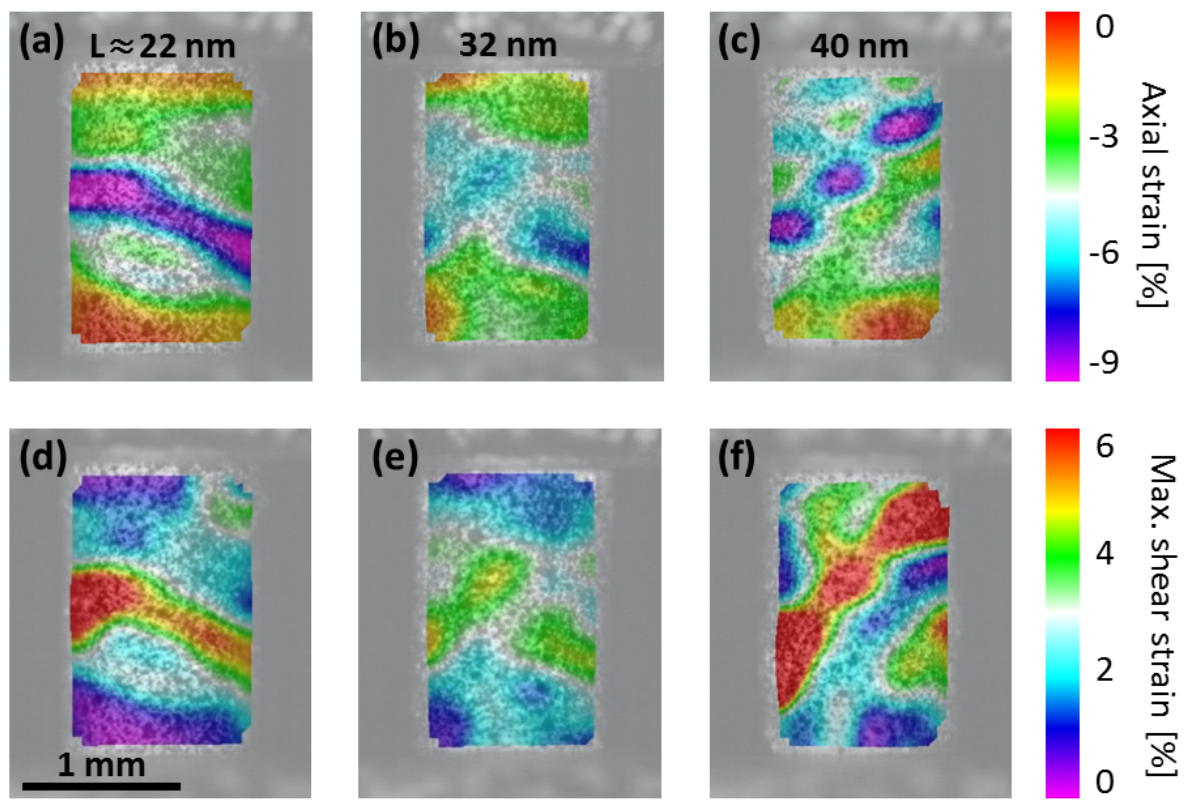

Figure 3: Strain maps of annealed nanoporous Copper-Nickel (npCN) under compressive loading at an average axial engineering strain of $4.4 \%$. Axial- (a-c) and maximum shear strain distribution (d-f) shown for npCN with a ligament size of $22 \mathrm{~nm}, 32 \mathrm{~nm}$ and $40 \mathrm{~nm}$, respectively. Localized deformation clearly visible.

\section{Acknowledgment}

This work was funded by the Helmholtz-Gemeinschaft through the Helmholtz-CAS Joint Research Groups, project HCJRG-315.

\section{References}

\section{References}

[1] Jin, H.J., Wang, X.L., Parida, S., Wang, K., Seo, M., Weissmüller, J.. Nanoporous AuPt Alloys As Large Strain Electrochemical Actuators. Nano Lett 2010;10(1):187-194.

[2] Detsi, E., Chen, Z.G., Vellinga, W.P., Onck, P.R., De Hosson, J.T.M.. Actuating and Sensing Properties of Nanoporous Gold. J Nanosci Nanotechnol 2012;12(6):4951-4955.

[3] Detsi, E., Onck, P., De Hosson, J.T.M.. Metallic Muscles at Work: High Rate Actuation in Nanoporous Gold/Polyaniline Composites. ACS Nano 2013;7(5):4299-4306.

[4] Stenner, C., Shao, L.h., Mameka, N., Weissmüller, J.. Piezoelectric Gold: Strong Charge-Load Response in a Metal-Based Hybrid Nanomaterial. Adv Funct Mater 2016;26(28):5174-5181.

[5] Wittstock, A., Zielasek, V., Biener, J., Friend, C.M., Baumer, M.. Nanoporous Gold Catalysts for Selective Gas-Phase Oxidative Coupling of Methanol at Low Temperature. Science 2010;327(5963):319-322.

[6] Jin, T., Yan, M., Menggenbateer, , Minato, T., Bao, M., Yamamoto, Y.. Nanoporous copper metal catalyst in click chemistry: Nanoporosity-dependent activity without supports and bases. Adv Synth Catal 2011;353(17):3095-3100.

[7] Xue, Y., Markmann, J., Duan, H., Weissmüller, J., Huber, P.. Switchable imbibition in nanoporous gold. Nat Commun 2014; 5:4237.

[8] Seker, E., Shih, W.C., Stine, K.J.. Nanoporous metals by alloy corrosion: Bioanalytical and biomedical applications. MRS Bull 2018;43(01):49-56.
[9] Jin, H.J., Weissmüller, J.. A Material with Electrically Tunable Strength and Flow Stress. Science 2011;332(6034):11791182.

[10] Ye, X.L., Jin, H.J.. Electrochemical control of creep in nanoporous gold. Appl Phys Lett 2013;103(20):201912.

[11] Mameka, N., Markmann, J., Jin, H.J., Weissmüller, J.. Electrical stiffness modulation - Confirming the impact of surface excess elasticity on the mechanics of nanomaterials. Acta Mater 2014;76:272-280.

[12] Sun, S., Chen, X., Badwe, N., Sieradzki, K.. Potentialdependent dynamic fracture of nanoporous gold. Nat Mater 2015;14(9):894-898.

[13] Lührs, L., Zandersons, B., Huber, N., Weissmüller, J.. Plastic Poisson's Ratio of Nanoporous Metals: A Macroscopic Signature of TensionCompression Asymmetry at the Nanoscale. Nano Lett 2017;17(10):6258-6266.

[14] Biener, J., Hodge, A.M., Hamza, A.V., Hsiung, L.M., Satcher, J.H.. Nanoporous Au: A high yield strength material. J Appl Phys 2005;97(2):024301-4.

[15] Volkert, C.a., Lilleodden, E.T., Kramer, D., Weissmüller, J.. Approaching the theoretical strength in nanoporous Au. Appl Phys Lett 2006;89(6):061920-1.

[16] Biener, J., Hodge, A.M., Hayes, J.R., Volkert, C.A., ZepedaRuiz, L.A., Hamza, A.V., et al. Size Effects on the Mechanical Behavior of Nanoporous Au. Nano Lett 2006;6(10):2379-2382.

[17] Briot, N.J., Balk, T.J.. Focused ion beam characterization of deformation resulting from nanoindentation of nanoporous gold. MRS Commun 2018;8(01):132-136.

[18] Kim, Y.C., Gwak, E.J., Ahn, S.m., Kang, N.R., Han, H.N., Jang, J.i., et al. Indentation size effect for spherical nanoindentation on nanoporous gold. Scr Mater 2018;143:10-14.

[19] Bürckert, M., Briot, N.J., Balk, T.J.. Uniaxial compression testing of bulk nanoporous gold. Philos Mag 2017;6435:1-22.

[20] Jin, H.J., Kurmanaeva, L., Schmauch, J., Rösner, H., Ivanisenko, Y., Weissmüller, J.. Deforming nanoporous metal: Role of lattice coherency. Acta Mater 2009;57(9):2665-2672.

[21] Ye, X.L., Jin, H.J.. Corrosion-Induced Strengthening: Development of High-Strength Nanoporous Metals. Adv Eng Mater 
2016;18(6):1050-1058.

[22] Mameka, N., Wang, K., Markmann, J., Lilleodden, E.T., Weissmüller, J.. Nanoporous GoldTesting Macro-scale Samples to Probe Small-scale Mechanical Behavior. Mater Res Lett $2016 ; 4(1): 27-36$.

[23] Jin, H.J., Kramer, D., Ivanisenko, Y., Weissmüller, J.. Macroscopically Strong Nanoporous Pt Prepared by Dealloying. Adv Eng Mater 2007;9(10):849-854.

[24] Shi, S., Markmann, J., Weissmüller, J.. Actuation by hydrogen electrosorption in hierarchical nanoporous palladium. Philos Mag 2017;97(19):1571-1587.

[25] Wada, T., Kato, H.. Three-dimensional open-cell macroporous iron, chromium and ferritic stainless steel. Scr Mater 2013;68(9):723-726.

[26] Kim, J.W., Tsuda, M., Wada, T., Yubuta, K., Kim, S.G., Kato, H.. Optimizing niobium dealloying with metallic melt to fabricate porous structure for electrolytic capacitors. Acta Mater 2015;84:497-505.

[27] McCue, I., Karma, A., Erlebacher, J.. Pattern formation during electrochemical and liquid metal dealloying. MRS Bull 2018;43(1):27-34.

[28] Okulov, I.V., Okulov, A.V., Soldatov, I.V., Luthringer, B., Willumeit-Römer, R., Wada, T., et al. Open porous dealloying-based biomaterials as a novel biomaterial platform. Mater Sci Eng C 2018;88:95-103.

[29] Hayes, J., Hodge, A., Biener, J., Hamza, A., Sieradzki, K. Monolithic nanoporous copper by dealloying $\mathrm{Mn}-\mathrm{Cu}$. J Mater Res 2006;21(10):2611-2616.

[30] Tang, B., Zhou, M., Zhou, R., Bai, P.F., Zhou, G.F.. WellOrdered Nanoporous Copper Fabricated by Dealloying $\mathrm{Cu}-\mathrm{Mn}$ and its Characterizations. Key Eng Mater 2016;693:662-668.

[31] Kong, Q., Lian, L., Liu, Y., Zhang, J.. Fabrication and compression properties of bulk hierarchical nanoporous copper with fine ligament. Mater Lett 2014;127:59-62.

32] Cheng, I.C., Hodge, A.M.. Morphology, Oxidation, and Mechanical Behavior of Nanoporous Cu Foams. Adv Eng Mater 2012;14(4):219-226.

[33] Egle, T., Barroo, C., Janvelyan, N., Baumgaertel, A.C. Akey, A.J., Biener, M.M., et al. Multiscale Morphology of Nanoporous Copper Made from Intermetallic Phases. ACS Appl Mater Interfaces 2017;9(30):25615-25622.

[34] Keil, P., Lützenkirchen-Hecht, D., Frahm, R.. Investigation of room temperature oxidation of $\mathrm{Cu}$ in air by Yoneda-XAFS. AIP Conf Proc 2007;882:490-492.

[35] Ives, D.J.G., Rawson, A.E.. Copper Corrosion. J Electrochem Soc 1962;109(6):447-451.

[36] Lambers, E.S., Dykstal, C.N., Seo, J.M., Rowe, J.E., Holloway, P.H.. Room-temerature oxidation of $\mathrm{Ni}(110)$ at low and atmospheric oxygen pressures. Oxid Met 1996;45(3-4):301-321.

[37] Davies, D., Barker, W.. Influence of $\mathrm{pH}$ on Corrosion and Passivation of Nickel. Corrosion 1964;20(2):47t-53t.

[38] Rosenberg, S.J.. Nickel and its alloys. Tech. Rep.; National Bureau of Standards Monograph 106; Washington; 1968.

[39] Hakamada, M., Mabuchi, M.. Preparation of nanoporous Ni and $\mathrm{Ni}-\mathrm{Cu}$ by dealloying of rolled $\mathrm{Ni}-\mathrm{Mn}$ and $\mathrm{Ni}-\mathrm{Cu}-\mathrm{Mn}$ alloys. J Alloys Compd 2009;485(1-2):583-587.

[40] Hakamada, M., Takahashi, M., Furukawa, T., Mabuchi, M.. Coercivity of nanoporous Ni produced by dealloying. Appl Phys Lett 2009;94(2009):15-17

[41] Dan, Z., Qin, F., Sugawara, Y., Muto, I., Hara, N.. Bimodal nanoporous nickel prepared by dealloying Ni38Mn62 alloys. Intermetallics 2012;31:157-164.

[42] Hakamada, M., Mabuchi, M.. Nanoporous nickel fabricated by dealloying of rolled Ni-Mn sheet. Procedia Eng 2014;81:21592164.

[43] Cheng, C., Lührs, L., Krekeler, T., Ritter, M., Weissmüller, J.. Semiordered Hierarchical Metallic Network for Fast and Large Charge-Induced Strain. Nano Lett 2017;17(8):4774-4780.

[44] Qiu, H.J., Kang, J.L., Liu, P., Hirata, a., Fujita, T., Chen, M.W.. Fabrication of large-scale nanoporous nickel with a tunable pore size for energy storage. J Power Sources 2014;247:896-
905.

[45] Bai, Q., Wang, Y., Zhang, J., Ding, Y., Peng, Z., Zhang, Z.. Hierarchically nanoporous nickel-based actuators with giant reversible strain and ultrahigh work density. J Mater Chem C $2016 ; 4(1): 45-52$.

[46] Needham, J.. Science and Civilisation in China; vol. 5, part 2 of Chemistry and chemical technology. Cambridge University Press; 1974. ISBN 9780521085717.

[47] Syrett, B.C.. Erosion-Corrosion of Copper-Nickel Alloys in Sea Water and Other Aqueous EnvironmentsA Literature Review. Corrosion 1976;32(6):242-252.

[48] Bendall, K.C.. Corrosion resistant alloys an industrywide overview of applications. Anti-Corrosion Methods Mater 1995;42(2):12-15.

[49] Gokcen, N.A.. The Mn-Ni (Manganese-Nickel) System. J Phase Equilibria 1991;12(3):313-321

[50] Gokcen, N.A.. The cu-mn (copper-manganese) system. J Phase Equilibria 1993;14(1):76-83.

[51] Bazhenov, V.E.. Phase diagram of the $\mathrm{Cu}-\mathrm{Ni}-\mathrm{Mn}$ system. Russ J Non-Ferrous Met 2013;54(2):171-177.

[52] Erlebacher, J., Aziz, M.J., Karma, A., Dimitrov, N., Sieradzki, K.. Evolution of nanoporosity in dealloying. Nature 2001;410(6827):450-453.

53] Bellet, D., Canham, L.. Controlled drying: the key to better quality porous semiconductors. Adv Mater 1998;10(6):487-490.

[54] Lührs, L., Soyarslan, C., Markmann, J., Bargmann, S., Weissmüller, J.. Elastic and plastic Poisson's ratios of nanoporous gold. Scr Mater 2016;110:65-69.

[55] Li, R., Sieradzki, K.. Ductile-brittle transition in random porous Au. Phys Rev Lett 1992;68(8):1168-1171.

[56] Parida, S., Kramer, D., Volkert, C.A., Rösner, H., Erlebacher, J., Weissmüller, J.. Volume change during the formation of nanoporous gold by dealloying. Phys Rev Lett 2006;97(3):4-7.

[57] Chen, F., Chen, X., Zou, L., Yao, Y., Lin, Y., Shen, Q., et al. Fabrication and mechanical behavior of bulk nanoporous $\mathrm{Cu}$ via chemical de-alloying of $\mathrm{Cu}-\mathrm{Al}$ alloys. Mater Sci Eng $\mathrm{A}$ 2016;660:241-250.

[58] Balk, T.J., Eberl, C., Sun, Y., Hemker, K.J., Gianola, D.S.. Tensile and compressive microspecimen testing of bulk nanoporous gold. JOM 2009;61(12):26-31.

[59] Yamada, Y., Banno, T., Xie, Z., Li, Y.C., Wen, C.E.. Preparation and Characterisation of Open-Cell Microporous Nickel. Mater Sci Forum 2007;539-543:1833-1838.

60] Taylor, S.L., Jakus, A.E., Shah, R.N., Dunand, D.C.. Iron and Nickel Cellular Structures by Sintering of 3D-Printed Oxide or Metallic Particle Inks. Adv Eng Mater 2017;19(11).

[61] Hakamada, M., Asao, Y., Kuromura, T., Chen, Y., Kusuda, H., Mabuchi, M.. Density dependence of the compressive properties of porous copper over a wide density range. Acta Mater 2007;55(7):2291-2299.

[62] Parvanian, A., Panjepour, M.. Mechanical behavior improvement of open-pore copper foams synthesized through space holder technique. Mater Des 2013;49:834-841.

[63] Greer, J.R., Nix, W.D.. Size dependence of mechanical properties of gold at the sub-micron scale. Appl Phys A Mater Sci Process 2005;80(8):1625-1629.

[64] Greer, J.R., Oliver, W.C., Nix, W.D.. Size dependence of mechanical properties of gold at the micron scale in the absence of strain gradients. Acta Mater 2005;53(6):1821-1830.

[65] Westwood, A.R.C.. The rebinder effect and the adsorptionlocking of dislocations in lithium fluoride. Philos Mag 1962;7(76):633-649.

[66] Gibson, L.J., Ashby, M.F.. Cellular Solids. Cambridge Solid State Science Series; 2 ed.; Cambridge: Cambridge University Press; 1997. ISBN 9781139878326.

[67] Bastawros, A.F., Bart-Smith, H., Evans, A.. Experimental analysis of deformation mechanisms in a closed-cell aluminum alloy foam. J Mech Phys Solids 2000;48(2):301 - 322 . 